\title{
The Educational Functions of Peer Groups in the Residential College
}

\author{
Yuan Tao \\ Faculty of Education, University of Macau, Macau 999078, China \\ marytaoyuan@gmail.com
}

Keywords: Peer groups, residential colleges, whole-person development, education, psychology.

\begin{abstract}
This paper focuses on the peer groups in the university residential colleges and their educational functions on the resident students. Residential colleges are different from traditional dormitories, offering more comprehensive services as well as social opportunities for students. The research method - authentic interview surveys are utilized to collect information. Moreover, previous studies and reliable theories are borrowed as supports for the research discoveries in this paper. Peers, as the closest companions in the university life, play a crucial role in students' improvement on information input, identity formation, psychological development and interpersonal skills. Though peer groups' educational functions undoubtedly exist in diverse aspects, potential disadvantages are also critically discussed at the end of the paper in order to avoid unilateral analysis on this topic.
\end{abstract}

\section{Introduction}

\subsection{Research Method and Research Discovery}

The reasons for choosing to investigate peer groups in the residential college originate not only from personal professional interest as an education-major student, but also from the intrinsic worth and exploratory potential of this topic. The residential college is a good entry point to discuss peer groups since it is separated from the formal classes, whose instructive significance is relatively unioriented; in the meanwhile, it covers wider possibilities of peers' interaction in different aspects in their life. As a member of resident students, this kind of experience can provide more authentic inspiration and empathy to boarders.

Primarily, this paper uses the interview survey as the research method containing three major advantages: flexibility, accuracy and depth. It is a process of two-way communication between an interviewer and an interviewee. The interviewer designs the survey questions in advance on the basis of the general situation plus the interviewer's subjective ideas, and some cases may not be considered thoughtfully or thoroughly; in this case, during the interview, the interviewer can flexibly vary questions according to an interviewee's response, Inquire more direct information if the feedback is implicit and guide the conversation timely when the interviewee misunderstands the questions. Besides, the interview environment is optional and controllable. The interviewer can properly avoid other disturbing factors, arrange the time of the interview, the rhythm of the conversation and the sequence of questions, and grasp the initiative of the interview process, which helps interviewees to answer the questions more objectively and accurately. The interviewees of this investigation include one resident fellow of Henry Fok Pearl Jubilee College of the University of Macau and five resident students.

Generally, the aim of this paper is to discuss the educational functions of peer groups in the residential college, and this assumption, successfully gets proved after the interview surveys with the assistance of diverse educational, psychological and sociological theories.

\subsection{The Introduction of Residential Colleges and Background of Residential Colleges in the University of Macau}

A residential college is an orderly organization which contains some academic programs, extracurricular activities, living accommodation, shared meals and other facilities. The establishment of residential colleges is based on the university system, but independent from the structure of university facilities; they own a degree of autonomy and a federated relationship with the overall university. Residential college systems are popular in Europe, North America and Chinese University of Hong Kong. They deliberately mix students of different majors together and allow them to live on 
campus during the academic years, aiming at promoting exchanges among students. Association is much more than students' living in the same space, but rather a persistent act of being connected with others in every corner of their school life.

Residential colleges in the University of Macau, arranged around a quad, are not just dormitories or hostels, but home-like groups of a few hundred of resident members. Every college has a college president, administrative officers, as well as some faculty fellows living in the residential college grounds near students, responsible for planning, managing and consulting tasks for the planning, managing and consulting tasks. The discussion of social events, the availability of academic supports, the organization of multi-cultural activities and common dining all connect the members of the residential college together, which can facilitate the connection among them and help them to grow fast. . Each college develops its own characteristics and styles, gradually turning into an animated place full of faith, individual freedom and debates about current events. The whole-person full development of students is always the goal: encouraging them to think independently, develop a global vision, and associate with other students successfully with ease. "Professional knowledge would be forgotten and obsoleted. However, the ability to interact and organize activities and the cultivation for culture and arts, physical education, and extra-curriculum development are of lifelong benefits. A full development with professional education, general education, social practice, internship, and peer education is the original intention of establishing the residential college system. . The university hopes that besides hard skills gained from the formal courses, students can obtain more soft skills from peer groups such as interpersonal skills and communication skills, which are very important in their future career development." (Fellow of the residential college) The network of personal relationships and friendships students develop in the residential college extend to continue for their later life as well.

\subsection{The Introduction of Peer Groups}

A peer group means a group of individuals sharing similar characteristics, interests (homophily), age, background, or social-economic status who are likely to influence a person's beliefs and behaviors. Peer group is an important environmental factor for individual growth and development in their life span. On the one hand, university students are more likely to form an educational and instructive group with their peers because they are in the same generation with less communication gaps and more similar interests. On the other hand, university students may be more willing to accept criticism and advice from peer group since they view things from more similar perspectives. Therefore, Peer groups not only have positive psychological effects on students such as companionship, sharing and confiding, but also improve their ability to socialize.

The resident students in the college can be considered as peer groups since their ages, educational level and cultural background do not differ a lot. They live together though they are from different majors and faculties so as to freely gather with congenial peers and form certain kind of informal interest groups.

\section{The Educational Functions of Peer Groups in the Residential College}

\subsection{To Shape Students' Personalities and to Form the Self-identity}

Peer groups can boost individuals' shaping their distinct personality and forming their own identity. Identity formation is a cognitive and developmental process where a person acquires a sense of self (i.e. individualization) and gets approved as a personal entity (The Free Dictionary, 2012) [1].

Erikson emphasizes that it is important to solve the crisis between identity formation and identity confusion (Friedman \& Howard, 2011) [2]. College students may struggle to find a balance between developing a unique individual identity while still being accepted and "fitting in". They have to determine who they want to be and how they want to be perceived by others. If they succeed, they will have a clear understanding of self-identity and become confident individuals who can freely associate with other people without losing their own identity. Otherwise, they will fail to be certain about self-identity and get socially disconnected from others; or, they may exaggerate the sense of own importance and adopt extremist positions. The peer group is one of the major factors influencing the process of self-identity formation. 
Peers are essential sources of information, including news, ideas and ideologies in students' life. The environment of the university is relatively an independent unity; in this case, for students in this unity, the access to the knowledge of current affairs and news is limited. "The residential college randomly distributes students from different regions of different majors to promote mutual exchanges so that those in the residential college will not be confined to communicate merely with students from the same major or the same class, which will help to broaden their horizons." (Student A, a junior student majoring in English Study) In the residential college, peers have more opportunities and free time to communicate with each other on different occasions, while having dinner, going to gym, attending the handcraft workshop together and etc. Members of the peer groups therefore provide diverse viewpoints outside the students' individual information scope and perspectives. To some degree, peers are increasingly becoming vital referents (Sherif, M., \& Sherif, C., 1964)[3] for teaching other members social norms, customs and ideologies as well (Clausen \& John, 1968)[4].

Mutual recognition and acceptance play vital roles in the effectiveness of peer groups. According to Maslow's Hierarchy of Needs Model, self-actualization, which refers to the desire of realizing personal potential, satisfying self-fulfillment, and seeking personal growth, is the highest level of need for people. Undoubtedly, self-identity is the base for self-realization while esteem is the second only to the need of self-actualization including two dimensions, both of which can be embodied in the process of peer group interaction. The internal dimension of esteem needs means that people are eager for personal strength, adequacy, confidence and achievement in the face of the world. The external dimension refers to the requirement of recognition, appreciation and importance. By getting along with peers who have similar ages, interests, and backgrounds, students develop personal personalities and get accepted by peer groups. When a member performs satisfying behaviors, the peer groups will give positive feedbacks. This In turn, this can encourage students to define themselves and do even better in the future. The differences of mindset and behavior model among members in the peer group also promote mutual influence and reinforcement, and therefore establish a clearer self-identity.

\subsection{To Cultivate Students' Social Skills}

Social skills are used by competent people to facilitate interaction and communication with others both verbally and nonverbally. In order to cultivate good interpersonal relationships and social skills, students need the assistance of peer groups to create a strong acquaintance and association with others.

Social anxiety disorder (SAD), also known as social phobia, is defined as the intense and persistent fear of being scrutinized, judged adversely or humiliated in social situations. Autism is also a kind of developmental disorder characterized by persistent difficulties with social communication and interaction (Landa RJ, 2008) [5]. Besides the genetics, environmental factors such as social experiences, cultural influences and interpersonal relationships are also the main causes of both disorders. The residential college holds diverse activities to offer more chances for students to communicate, collaborate and interact with peers. "Our college is a multi-disciplinary college with a wide range of activities and workshops such as English Corner, make-up training, baking, handicrafts, art appreciation, and business lectures which can be chosen to participate according to personal interest. A high-quality activity is really worthwhile. Through these workshops, students can makenew friends, explore new fields and access to information on the leading edge." (Student D, a junior student majoring in Business Administration) A positive and stable relationship with peers can prevent or release these problems. What is more, effective communication (correctly reading others, recognizing others' feelings and intentions, and appropriately expressing own emotions) among peers increase the interpersonal strategies to a large extent. "The residential college system is different from ordinary independent dormitory and canteen. With social functions, it provides a platform for students to communicate with each other and socialize, promoting social skills and knowledge through a variety of activities" (Student C, a junior student majoring in Sociology)

Moreover, student leadership system indicates the hierarchy of peer groups. "It is impossible for residential colleges to be developed and shaped entirely by the president, officers and fellows. It is the student leaders that make the atmosphere so active." (Fellow of the residential college) Student leaders help to organize the operation of the residential college and take on the responsibility to spread 
information and knowledge through tutoring, inspiration and campaigns. They strive to improve the residential college through their insight, leadership, assertiveness and conscientiousness, all significant for the development of social skills.

\subsection{To Establish and Maintain a Positive State of Emotions and Mentality}

According to Maslow's Hierarchy of Needs Theory, humans need to feel love and belongingness. The residential college provides a platform for students to seek for groups and a sense of community, also allowing them to ease loneliness. "One advantage of the residential college is that the daily life of students (their eating and living) are organically linked together to form an overall cohesion of the college and students' sense of belonging to the college." (Student E, a junior student majoring in Preprimary Education) In fact, the need to belong and the sense of belongingness is ingrained innately and may be intense enough for the establishment of a sound emotional state.

According to Self-determination Theory, relatedness is one of the three personal psychological needs. Students need to be connected to and experience caring from others. Peers in the residential college give other members the sense of safety through mutual respect, trust, support, concern and tolerance.

"The biggest highlight of the residential college system is that it is more convenient for management and helpful to create a distinctive atmosphere for students better getting along with others." (Student B, a senior student majoring in Sociology) Living in the same residential college, peers usually bring happiness to each other. In addition to play a starring role in some of the most valuable memories, they also make their peers burst into laughter when they are down in dumps. Happiness is contagious and peer groups are the transmitter. They enrich students' life profoundly in meaningful ways.

\subsection{Peer Groups as a Type of Supplement and Substitution}

Peer groups can be considered as a type of supplement and substitution in different cases. In the first place, the educational function of peer groups in the residential college is a supplement to the formal classes; it is a kind of informal learning, which does not need to be delivered by trained teachers in a systematic intentional way. This kind of education unconsciously incidental or consciously intuitive, takes place outside the university course establishments and is not necessarily planned systematically or pedagogically in accordance with fixed qualification-oriented subjects and exams; but rather, it is more holistically situation-connected, and connected to real problems and fitness for life. "Residential colleges and academic faculties interwork and cooperate to make a big difference in one's building confidence." (Fellow of the residential college)

To some extent, peer groups in the residential college substitute the function of families. There is obvious that the residential college creates a more home-like community and environment for students when they leave their homes and live together in the university. Peers seem to be students' siblings and they are all an entirety. Living accommodation and facilities such as the dining hall, the gym, the laundry, the instrument room and the billiard table are collectively provided for daily convenience. The harmonious atmosphere of the residential college makes sure that students feel at home even if they are far away from their hometowns.

The residential college is also the epitome of the society reflecting abundant social norms and rules of development of humans' life. First, it serves as a rehearsal venue to adulthood for students. Peer groups in the residential college offer buttress as adolescents assimilate into adulthood and certain changes occur within the community, including depending less on parents, interacting with an increasingly larger social net-work and experiencing higher self-sufficiency (Blos, 1967; Erikson, 1968; Newman, 1967) [6][7][8]. Students expand perspectives beyond their previous environment such as the small family and learn how to integrate in a bigger society, deal with new problems and negotiate with others in different parts of the social system. Second, the residential college imparts some collective norms and behaviors, which are important for students' further development in the society. Peer groups provide a special and specific social setting where group consciousness is emphasized and implemented through the socialization noesis that enhances the similarity within the groups such as joint endeavor and resonance (Eder \& Nenga, 2003) [9]. Therefore, the cohesion of 
peer groups is established and maintained by catalysts like frequent group communication, consensus, consistency and conformity.

\section{Critical Analysis: Potential Disadvantages of Peer Groups in the Residential College}

However, peer groups in the residential college also have some potential threats and negative attributes. Peer pressure is the direct influence on students who are encouraged to follow their peers by changing their own values and behaviors in order to conform to and get involved into the group. Although it is positively supportive, it has negative effects as well. For instance, pressure from peer groups can lead to stress, prejudice, vanity, class-skipping, stealing, cheating, drug or alcohol using and other risky behaviors. Risky behaviors are contagious. Peers largely replace families in terms of many leisure activities and social communications, and peer groups therefore become mighty agents of problematic behaviors, which mainly occurs in the context of peer groups, among students.

A successful peer relationship touches on students' later development, including psychological modification, academic achievements and career prospects. If students have an unpleasant peer relationship, it may evolve some derivative problems such as developmental delays, poor concentration, and lack of confidence or depressive attitudes (Curtis, Tepperman, \& Albanese, 2008) $[10]$.

\section{Conclusion}

According to the aforementioned respects, peer groups' educational functions in the residential college cannot be overlooked. In this paper, several interviewees are chosen to excavate more and deeper information about the topic based on some relevant theories in the field of education. Through the research, it can be discovered and concluded that the residential college helps to create a mild atmosphere for socializing and students' integrating into the society; peer groups, hopefully, promote Personality shaping the self-identity and a healthy mental state among university students. Although so wonderful peer groups are, it should not exaggerate the merit of wide interaction with peers and ignore the potential threats of doing so. Proper measures should be taken to solve the problems among peers' association with each other, namely making use of more professional knowledge and interpersonal experience to create a more sustainable peer-coexisting environment.

\section{References}

[1]. Peer group. (n.d.). Dictionary.com. Retrieved October 25, 2012, from http://dictionary.reference.com/browse/peer+group The Free Dictionary (2012). "Individuation". Retrieved 11 October 2012.

[2]. Friedman, Howard (2011). Personality: Classic theories and modern research. Boston, MA: Allyn \& Bacon. pp. 131-135.

[3]. Sherif, M., \& Sherif, C. (1964). Reference groups. Chicago: Regnery Youniss, J., \& Smollar, J. (1985). Adolescents' relations with mothers, fathers, and friends. Chicago: University of Chicago Press.

[4]. Clausen, John A. (ed.) (1968) Socialization and Society, Boston: Little Brown and Company. p5, "Social anxiety disorder." CareNotes. Truven Health Analytics Inc., 2012. Health Reference Center Academic. Web. 15 Nov. 2012.

[5]. Landa RJ (2008). "Diagnosis of autism spectrum disorders in the first 3 years of life". Nat Clin Pract Neurol. 4 (3): 138-47. doi: 10.1038/ncpneuro0731 Freely accessible. PMID 18253102.

[6]. Blos, P (1967). "The second individuation process of adolescence". The Psychoanalytic Study of the Child. 22: 162-186.

[7]. Erikson, E. H. (1968). Identity: Youth and crisis. New York: Norton. 
[8]. Newman, B. M.; Newman, P. R. (1976). "Early adolescence and its conflict: Group identity versus alienation". Adolescence. 11: 261-274.

[9]. Eder, D., \& Nenga, S. K. (2003). Socialization in adolescence. In J. Delamater (Ed.), Handbook of social psychology (pp. 157-182). New York: Kluwer Academic.

[10]. Curtis, J. E., Tepperman, L., \& Albanese, P. (2008). Socialization. Sociology: a Canadian perspective (2nd ed., p. 112). Don Mills, Ont.: Oxford University Press. 